\title{
A vivência dos coordenadores de curso de Enfermagem em relação ao Sistema Nacional de Avaliação do Ensino Superior (SINAES)
}

\author{
The experience of Nursing courses coordinators in regard to the national \\ Evaluation System of Higher Education (SINAES)
}

\begin{abstract}
O Sistema Nacional de Avaliação da Educação Superior (SINAES) tem a função de avaliar as instituições de Ensino Superior e os cursos por elas oferecidos, como os cursos de enfermagem. O SINAES está presente nas atividades gerenciais dos coordenadores de curso. Este estudo teve como objetivos: conhecer a vivência dos coordenadores de curso de graduação em enfermagem em relação ao Sistema Nacional de Avaliação do Ensino Superior (SINAES); identificar as influências dessa vivência na prática,
\end{abstract} enquanto coordenadores de curso, e descrever como são utilizadas as informações geradas por esse sistema no gerenciamento de curso. Tratouse de um estudo exploratório, descritivo, com abordagem qualitativa. Os sujeitos envolvidos foram 6 coordenadores que vivenciaram o SINAES. Os discursos foram obtidos por meio de 3 questões norteadoras: "Como você descreve a sua vivência no SINAES? O que esta vivência influenciou na sua prática enquanto coordenador(a) de curso? Como você utiliza as informações do seu curso geradas pelo SINAES?". Os resultados revelaram que as vivências foram relatadas por meio das ações e percepções que se relacionavam à operacionalização, organização e preparação dos processos gerenciais requeridos pelo SINAES, no âmbito do curso; as influências dessa vivência foram identificadas tanto no gerenciamento acadêmico, nas questões voltadas para a articulação de avaliação e implementação do projeto pedagógico do curso (PPC), quanto nas questões administrativas requeridas pela universidade; os coordenadores utilizavam as informações geradas pelo SINAES na organização didático-pedagógica, nas ações que envolviam o corpo docente, corpo discente e corpo técnicoadministrativo, e na organização e provisão da estrutura física. Pode-se constar que as vivências dos coordenadores, em relação ao SINAES, demonstraram a participação direta dos entrevistados nos processos avaliativos, o que
Ihes permitiu analisar e identificar, juntamente com os atores envolvidos, os problemas acadêmicos e administrativos do curso e, posteriormente, planejar e realizar mudanças. Assim, acreditamos que o conhecimento das vivências dos coordenadores, a identificação das influências e a descrição das utilidades do SINAES possam colaborar com os processos gerenciais do curso de enfermagem; e que, a partir destes resultados, abram-se caminhos para a construção de indicadores de qualidade que possibilitem mensurar a efetividade das ações realizadas.

\section{Alessandra Santos de Paula Dissertação (Mestrado), 2009 Programa de Pós-Graduação em Enfermagem, Escola de Enfermagem, Universidade de São Paulo alessandrass_paula@yahoo.com.br}

Palavras-chave: Educação em Enfermagem. Avaliação do Ensino Superior. Sistema Nacional de Avaliação do Ensino Superior (SINAES).

Keywords: Nursing (Education). Higher Education (Evaluation). National Evaluation System of Higher Education (SINAES).

Palabras clave: Enfermería (Educación). Educación Superior (Evaluación). Sistema Nacional de Evaluación de la Educación Superior (SINAES).

Texto completo disponível em:

<http://www.teses.usp.br/teses/disponiveis/7/7131/tde07072009-095515/pt-br.php> 
